\title{
UNA REFLEXIÓN SOBRE \\ EL PROYECTO DE CREAR \\ UNA FACULTAD DE \\ CIENCIAS SOCIALES
}

Roberto Escobar B.

Los cambios no asustan a los científicos sociales, el estudio de la sociedad es el estudio del cambio y el desarrollo de la colectividad nacional es un cambio necesario. Toynbee usa la famosa frase del Evangelio: "No hay que echar vino nuevo en odres viejos", para explicar que la fuerza de la fermentación del vino nuevo rompe las paredes debilitadas de los odres viejos y la vitalidad de la vida nueva se desparrama y se pierde. Así también ocurre con las instituciones sociales, una vez que quedan obsoletas si siguen recibiendo el chorro vital de la nueva vida, se desarticulan. Por esto, para lograr un cambio en la sociedad, hay que crear instituciones nuevas, fuertes para resistirlo.

Pienso que eso es lo que ha ocurrido con la universidad chilena; quienes quieran entender la voz de la nueva vitalidad, podrán constituir los "odres nuevos" para el espíritu del futuro. Quienes añoren en demasía el pasado, corren el riesgo de romperse bajo la nueva presión.

Todo cambia y todo evoluciona; no sólo el mundo está en movimiento, como su antecedente, se mueven también las ideas cargadas de la energía psíquica que todo lo puede si es adecuadamente aplicada. La universidad también cambia, tiene obligación de cambiar, es necesario que cambie. Sus profesores y alumnos deben aprender a evolucionar con ella y aportar sus propios pensamientos a la realización de cambios favorables. El permanente cambio y adaptación de la universidad a la sociedad le permiten ser el vehículo idóneo en la conservación del saber y de la cultura y con ello constituirse en el asiento mismo de nuestra identidad como personas y como pueblo; en una palabra, de la nacionalidad.

Para la universidad el estar en permanente evolución resulta de la necesidad de abocarse a la reflexión para responder a las preguntas esenciales. Dentro del 
ámbito universitario es propia y pertinente la pregunta sobre el ser de la universidad misma, de quienes la forman y el "porqué" de las disciplinas que en ella se desarrollan. Es necesario que nos preguntemos, en nuestro particular ámbito, una y otra vez por el propósito y las metas de las Ciencias Sociales: ¿Cuál es la finalidad de la sociología, la antropología, la psicología y la arqueología? ¿Son las Ciencias Sociales sólo "profesiones" destinadas a "vender" técnicas de diagnóstico? Pienso que no. La sociedad es un campo vivo, lleno de contradicciones, su estudio es difícil y no basta dominar las técnicas de observación y medición; hay que conocer el alma de la sociedad.

Curioso problema. ¿Cómo se conoce el alma de algo o de alguien? Un camino es visualizarlo todo como si fuera uno mismo, es decir, proceder por analogía con lo subjetivo. Otro camino es proceder por un modelo de alma, construido con elementos conceptuales. Aún queda un tercer camino, proceder por comparación entre las manifestaciones de las almas, en el plano objetivo.

Este es un lenguaje poco usual en las Ciencias Sociales, es lo que uno podría encontrar leyendo a los griegos, a los romanos y a los humanistas del Renacimiento, pero hoy en Chile nos parece raro. Sin embargo, no es más que la única formulación del problema ante el materialismo creciente, que tiende a tomar la sociedad como un hecho objetivo y desconocer la fuerza e influencia del subconciente colectivo. Ocurre que el alma de un pueblo -en este caso, el alma de Chilese expresa en la universidad; a través del diálogo entre profesores y alumnos se produce el cruce de los caminos y los intereses: lo viejo y lo joven; el saber y la inquietud; la experiencia y la potencialidad.

El verdadero sentido de la educación universitaria es producir un aprendizaje, no realizar una enseñanza; su acción propia descansa en comprender que no sólo los estudiantes aprenden, sino que los profesores deben comprender su obligación como un permanente estudio. Dicho en forma más explícita: la universidad es un "lugar" (campus) donde "toma asiento" (sede) la autoridad intelectual. Lugar y asiento donde se dan y se reciben "los saberes" en el sabroso castellano del rey Alfonso el Sabio.

Todos, profesores y alumnos hemos venido aquí a recibir "los saberes". Creo que lo mejor que he aprendido me lo han enseñado mis alumnos. No es un elogio gratuito, hay muchos muy mediocres, pero todos tienen algo que decir y aportar $y$ todo científico social sabe mantener los ojos y oídos abiertos a lo nuevo que lo rodea. Pero el "saber los saberes" no basta para una universidad que va llegando al año 2000.

Inserta en una sociedad, la pequeña comunidad universitaria tiene una obligación especial: prever y pensar el devenir de la vida y la sociedad.

La tarea de formar profesionales para la vida industrial y comercial puede ser asumida por institutos especializados, pero la formación de humanistas es privativo de las universidades. 
¿Y para qué sirve un humanista?

Si de utilidad práctica se trata, no hay duda que el barrendero que limpia la ciudad es más útil. Pero, ¿quién estudiaría el cambio si no existiera el humanismo? ¿Y si no se estudia el cambio, cómo conocer la vida? ¿Y si no se conoce la vida, cómo se puede saber qué somos nosotros mismos? ¿Y si no sabemos lo que somos nosotros mismo, para qué sirve existir? O sea, parece que el humanismo fuera en cierto modo - si no útil- necesario.

Su finalidad es el perfeccionamiento de la humanidad. Lograr la evolución que lleve a la sociedad a los más altos niveles éticos posibles. Por eso todo proyecto humanista supone el análisis comparativo de las sociedades y sus culturas, intentando conocer aquéllo tan difícil de conceptualizar, que es el "alma" de la sociedad.

Ya en el Renacimiento los humanistas previeron la necesidad de formular modelos sociales, determinando con bastante exactitud la naturaleza del Estado, las formas y maneras de la participación política, las obligaciones y objetivos de las personas en sus diversos roles sociales, incluso conceptualizando ciertas clases de hombres de trabajo y los métodos educacionales para cada uno.

Todo esto con los proyectos sociales antiguos a la vista, con la experiencia de un análisis histórico de dos mil años, desde la cultura griega hasta su reformulación en el Renacimiento y su proyección hacia América.

Hay una tendencia a crear modas en las Ciencias Sociales, como si se tratara de algo recién descubierto o en proceso de elaboración. Los problemas y coyunturas de la sociedad son repetitivos, la Historia se encarga de mostrarlo con incómoda frecuencia. Las soluciones a esos problemas y coyunturas se conocen, y también el resultado que tuvieron, sin embargo, nada es igual en la vida y si bien las situaciones históricas se presentan en forma repetitiva, los hombres que actúan no son los mismos y la subjetividad que entra en el problema ineludiblemente carga las tintas en algún sentido. Esto hace posible que la experiencia de la humanidad sea estudiada, comparada y reformulada. Las Ciencias Sociales son tan antiguas como el hombre, si bien en sus aspectos formales pueden aparecer como constituidas recién en el siglo pasado y desarrolladas en el actual.

El estudio del pasado es necesario, para el temperamento humano y los estudios prehistóricos apoyados en las comprobaciones arqueológicas aparecen en todas las culturas que se pregunten por su origen y procedencia.

Si bien vivimos una era de pobreza en la producción monumental y artesanal podemos admirarnos, no sólo científicamente sino artísticamente, ante los edificios, adornos y textiles de pueblos que tenemos la audacia de creer "retrasados" respecto de nosotros.

El saqueo a que se ha sometido a Egipto en las dos últimas centurias, mayor que el realizado por los romanos, tiende a dar aire de espectacularidad a la arqueología, y si agregamos a ello el romanticismo literario de arqueólogos como Schliemann, quien logra desenterrar Troya, resulta claro que la inquietud científica 
aparece siempre mezclada con la admiración artística, y que el estudio del pasado es una forma especial del estudio de nosotros mismos.

América es depositaria de un pasado prehistórico muy diferente del Mediterráneo, pero no menos importante, ni en monumentalidad ni en la perfección artística; para mi gusto muy superior a otros continentes. Es nuestro legado cultural y le debemos prestar especial atención - pero no creamos que la arqueología es una ciencia reciente en que están apareciendo "novedades" gracias a la metodología. Es verdad que el auxilio de la físico-química y la biología permiten, hoy, hacer estudios que no habrían logrado ni Schliemann, ni Evans, ni Carnarvon, pero todo ello sólo va en abono del punto importante: estudiar el pasado para conocernos mejor nosotros mismos.

La expansión colonial europea desarrolló, por necesidades de gobierno, el estudio de los pueblos y de las culturas, es decir, la Antropología.

La ocupación de una enorme área por el Imperio Romano sólo era posible por el estudio, descripción y análisis de los diferentes pueblos, de lo contrario habría sido imposible su cohesión interna. Cuando decayó el estudio antropológico de su propia realidad, se desmembró.

La admirable jurisprudencia romana, modelo hoy para todas las legislaciones del mundo, sólo se pudo desarrollar como el resultado de un profundo estudio sociológico, muy bien hecho. Una obra clásica: Las vidas de hombres ilustres, de Plutarco, ¿qué es, sino un admirable análisis socioantropológico, incluso en su estilo y método?

No hay otra explicación, para el hecho de que un puñado de ingleses mantuvieran a toda la India dominada - por medio de contraponer intereses religiosos, económicos y culturales entre los principados-, que el uso de la antropología aplicada, disciplina en la cual los ingleses siempre han descollado.

En el Imperio Español pasaba otro tanto, cada expedición castellana y cada ciudad tenía un cronista, un escribiente que observaba y anotaba. No eran otra cosa que informes antropológicos y sociológicos; hoy los miramos como documentos históricos y creemos que se escribieron para la posteridad, cuando en realidad eran informes científicos sobre la actualidad americana que eran estudiados, sopesados y servían para determinar medidas de gobierno muy exactas.

Durante los siglos XVII y XVIII, América es visitada por franceses, alemanes e ingleses cuyas crónicas y memorias, incluyendo mapas y dibujos, son admirables informes de estudio antropológico.

Podría dar tantos ejemplos... La famosa Biblioteca de Alejandría, que fue quemada, era un archivo de información científica, el registro de todo lo ocurrido a la humanidad, indagado con rigor y método por los sacerdotes del delta del Nilo. Allí acudían como a una gran universidad muchos hombres, decisivos en el desarrollo de los pueblos del Mediterráneo: Menelao, Pitágoras de Samos, Alejandro de Macedonia, Solón, para ellos fue un verdadero faro del saber social. 
La educación en el pasado incluyó siempre a las Ciencias Sociales, salvo que no usaban los nombres que hoy conocemos. Los romanos estudiaban el desplazamiento rural-urbano e intentaron legislar para dirigirlo adecuadamente y la demografía es también una ciencia que ya era madura a principios de la era cristiana.

Todo esto permite observar que las Ciencias Sociales siempre han estado presentes en el campo más amplio del humanismo y que sin ellas el humanismo no se constituye integralmente.

Los modelos de la antigüedad bien vale tenerlos en cuenta; los antiguos, de alguna manera, lograron conocer el alma de su sociedad.

Cuando el europeo embriaga su espíritu con las ciencias experimentales y hunde su mirada en la naturaleza —olvidando que al hundirse se pierde el sentido de dirección-durante el siglo xvIII comienza el divorcio de las Ciencias Sociales del saber general. Fue esto lo que provocó el desarrollo de ciencias especiales para considerar la sociedad.

Hoy, la Sociología, la Psicología y la Antropología son especialidades - hasta el punto de haber alcanzado el nivel de profesiones.

El problema está en que para justificar su carácter de profesiones independientes, han vuelto la espalda a la sociedad misma que estudian: se intenta conocer lo urbano, como si lo rural no existiese; tendemos a desesperarnos porque los pascuenses evolucionan y se modernizan tan rápido, que no alcanzamos a registrar lo que eran hace unos pocos años.

¿Acaso no es más importante la modernización de la humanidad? ¿No es el bienestar de los pascuenses de hoy más importante que las tradiciones de sus antepasados?

El problema está en el "alma" de la sociedad. Si la modernización se contrapone con el "alma", es dañina. Si coincide con ella es beneficiosa. Pero para saberlo habría que conocer la esencia de la sociedad.

Hay que precaverse de la idea de que hay "ciencias nuevas". El caso más evidente de los errores que se producen es el de la economía, ciencia que en su origen es parte de las Ciencias Sociales y del Humanismo y que, al transformarse en la tecnología del dinero, se aleja cada vez más del hombre, introduciendo en las culturas fundadas en el espíritu, la idea de que la ganancia material es un prestigio.

El crecimiento de la humanidad hizo necesario inventar el dinero como medio de cambio, pero ya hoy el dinero es un bien en sí, se compra, se vende, se arrienda, tiene un doble valor: el de cambio y el propio de las finanzas. Incluso llegamos a hablar de moneda imaginaria: Ios euro-dólares, las Unidades del Fondo Monetario, las Unidades de Fomento, etc.

Ante esto, sólo se puede preguntar: ¿Y el hombre, dónde está?

Los antiguos señalaron tajantemente que el dinero no puede producir, por sí solo, dinero (Platón); que el interés sobre el capital es contrario a la naturaleza (Aristóteles); siglos más tarde Adam Smith, "el padre del capitalismo", señala que 
el dinero debe servir al hombre, es decir, el dinero ahorrado constituye un capital destinado a producir bienes que mejoren la sociedad. El interés excesivo dilapida el capital y por ello es injusto y prácticamente inconveniente, ningún negocio "honrado" - dice - puede producir lo suficiente para una tasa de interés superior al $6 \%$ al año, por lo cual la usura es un daño social que menoscaba la capacidad productiva de un pueblo. La técnica económica de hoy va por otros caminos, se cierra sobre sí misma y sin el análisis de la realidad social, comete a menudo errores que repercuten, con perjuicio, en los hombres a quienes pretende servir.

El tema de la economía figura junto a otros intereses sociológicos en la obra del más destacado humanista que ha producido Alemania, Johann Wolfgang Goethe. Su extensa obra cubre todas las gamas del humanismo y su vida misma es la integración riquísima de toda clase de experiencias de observación y análisis de la vida dentro del plano social, histórico y subjetivo. Si bien se diría que su medio principal de expresión fue el literario o, más exactamente, lo escrito; Goethe también conoció y practicó las artes plásticas, adquiriendo un contundente conocimiento técnico sobre color y volumen. Por otra parte, su afición a la música es reconocida. Era un hombre abierto a todo, un humanista ejemplar cuyas condiciones y obras valen la pena recordar en esta hora.

Entre sus preocupaciones científicas, son conocidas su espléndida Teoría de los Colores y sus divergencias con Newton en asuntos de Óptica. Estudioso de Linneo, se ocupa de la Botánica y luego de la Zoología, que lo lleva a los problemas del "origen del Hombre", que discute con Herder, y las investigaciones sobre el hueso intermaxilar que lo vinculan directamente a la Antropología Física. En el campo interdisciplinario de la Sociología con la Arquitectura nos dejó sus comentarios a la obra de los hermanos Boisserée en la Catedral de Colonia, lo que le permite reflexionar sobre aspectos del "estilo alemán" - siendo el "estilo" una de las manifestaciones del "alma" de la sociedad. También demuestra su poderosa síntesis y su potencial humanista en sus Confidencias sobre Geologia en la cual, por medio de datos autobiográficos, nos traza el sentido de la Geología como una manera de entender la situación de uno mismo en el mundo. Otra vertiente de ciencia social aparece en sus extensos diarios y escritos autobiográficos que contienen admirables descripciones propias de la Antropología Cultural y de la Psicología Social. Sus estudios sobre la guerra, en la cual participa como oficial, son las observaciones de un científico social.

Su obra literaria, subjetiva en lo poético, resulta de la forma simbólica de presentar las situaciones sociales y como ejemplo quiero remitirme a una obra poco conocida y raramente representada, me refiero a la Segunda Parte del "Fausto". Si bien todos conocen la primera parte, el pacto de Fausto con Mefistófeles, el amor del anciano por la mujer joven y la salvación que alcanza ésta en su muerte; pocas veces se representa la Segunda Parte que es muchísimo más interesante y que revela una visión social de la humanidad del mayor interés. 
Fausto participa en diversos encuentros, algunos objetivables, otros míticos, pero cuyo simbolismo social es claro.

Después de la aventura con Margarita, Fausto pide y obtiene de Mefistófeles conocer, nada menos, que a Helena, la hermosa que desató la Guerra de Troya; además, Fausto conoce y conversa con el Homúnculo, que no es otra cosa que un niño de probeta, jesto escrito en 1830 !

Con humor fino y conocimiento exacto de asuntos económicos, también avanzados para su tiempo, se plantea en la misma obra lo que podríamos llamar: Goethe y la Inflación. En escenas de mucho humor, se presenta a un emperador imaginario acosado por sus ministros que requieren dinero, que el emperador no tiene - lo que hoy llamaríamos simplemente una situación de Déficit Fiscal. Mefistófeles inventa una "diablura", la de convencer al Ministro de Hacienda de hacer circular unos vales firmados por el emperador que equivalen a cierto valor en oro y cuyo respaldo son los tesoros inagotables que hay bajo la tierra. En la escena siguiente se nos muestra al pueblo feliz en plena actividad pero, los cambistas al cambiar los billetes por metálico lo hacen ya con un cierto descuento -es decir, Goethe nos está describiendo la inflación en la misma forma que un siglo después lo haría el economista inglés Keynes, y establece con exactitud el problema del "patrón oro" que promovió las crisis monetarias de la postguerra en la década de 1920 y que aún repercute en el precio del petróleo hoy: El emperador, sus ministros y hasta el astrólogo de la corte, declaran su conformidad; quedando ésta como otra de las trastadas de Mefistófeles en contra de los hombres.

Esto daría para muchos análisis, pero sólo lo traigo a colación para entender que el campo de la economía, al prescindir hoy de la integración a las Ciencias Sociales pierde una parte importante de su enfoque, y que sólo el humanismo es la forma más completa y acertada de estudiar la sociedad, siempre integrado con las Ciencias Sociales. Al mismo tiempo que la economía, se alejan los problemas derivados del campo biológico -en especial los de la salud, que tanto en los estudios de población actual como en la Paleontología necesitan cada día más una integración con las Ciencias Sociales.

El lugar (campus) donde debe asentarse (sede) la integración de las disciplinas es la universidad. Si no existiese no seria posible la multidisciplina que pueda formular medidas de mejoría en el campo de la salud, educación, vivienda, con todos sus derivativos: nutrición, familia, bienestar, y más que todo ello, armonía social.

Es necesario volver a considerar, para este enfoque, la definición de universidad que da el DFL 1 del 30 de diciembre de 1980 , en su artículo $2^{\circ}$ y que contiene los conceptos por los cuales debemos orientar nuestra tarea. Tiene cuatro incisos, dice en los dos primeros:

a) Promover la investigación, creación y preservación del saber universal y el cultivo de las artes y las letras. 
b) Contribuir al desarrollo espiritual y cultural del país, de acuerdo a los valores de su tradición histórica.

A esto podemos comentar que precisamente el desarrollo del espíritu y de la cultura requieren el aporte de las Ciencias Sociales, y que la preservación y transmisión del saber -el famoso "saber los saberes" a que ya he aludido- necesitan de normas y procedimientos que no se podrían establecer sin el análisis diagnóstico socioantropológico. Al hablar de los valores de nuestra tradición histórica ¿no estamos estableciendo una corriente de pensamiento que no puede excluir todo nuestro pasado, incluyendo lo prehistórico? Queda así, muy en claro, la tarea necesaria que las Ciencias Sociales deben aportar al desarrollo cultural global que plantea el Decreto que comento.

En el inciso siguiente dice:

c) Formar graduados y profesionales idóneos, con la capacidad y conocimientos necesarios para el ejercicio de sus respectivas actividades.

A esto habría que precisar que nuestro quehacer no se detiene en las especulaciones ni puede estar orientado exclusivamente al cumplimiento de satisfacciones personales, sino que se justifica por sus egresados y su idoneidad para utilizar las Ciencias Sociales positivamente en la solución de los problemas que plantea el desarrollo equilibrado de la sociedad chilena y americana.

Hago hincapié en que el decreto señala precisamente el requisito de la "idoneidad". Si nuestros egresados no están adecuadamente preparados para desempeñarse en el campo aludido, no estaríamos cumpliendo con una de las exigencias que nos hace un centro universitario. No se crea que este es un asunto simple. Por el contrario, aquello que hace "idóneo" a un cientista social es la capacidad para comprender lo esencial de la sociedad y para sopesar el efecto cultural de las medidas que se proponen. El manejo de las metodologías debe ser exacto y adecuado; y las metodologías, deben aplicarse a problemas claramente delimitados; $y$ la delimitación de los problemas supone la adecuada habilidad para estudiar, en abstracto, hipotéticamente, el asunto; y el estudio abstracto supone a su vez la concurrencia de dos habilidades muy específicas; el dominio del pensamiento teórico y la aguda sensibilidad para la observación.

La universidad no puede cambiar las aptitudes, puede, eso sí, perfeccionar las habilidades. Pero lo que es privativo de la universidad es la transmisión de los fundamentos teóricos y el adiestramiento en el raciocinio, tanto con elementos racionales como irracionales.

Debemos formar egresados idóneos. Esto nos lleva a establecer métodos y programas de estudio cada vez más perfectos, aumentando necesariamente las exigencias, pues de lo contrario dejaríamos de ser una universidad. Cuando se habla de elevar el nivel académico y de aumentar las exigencias de los estudios, en realidad se habla de algo mucho más complejo y trascendente que los aspectos 
didácticos, tales como tomar más pruebas o exigir más lectura a los alumnos; se trata de que la unidad académica entera debe ampliar y profundizar el campo de sus investigaciones y estudios. Debe establecer con claridad sus objetivos y revisar sus procedimientos desde el punto de vista de la idoneidad ya señalada.

La universidad debe entrar en contacto abierto con la sociedad, es decir, debe estudiar la realidad social objetiva y científicamente, especialmente a través del cultivo de las Ciencias Sociales.

En un mundo de creciente especialización técnica, se va perdiendo el cultivo de las disciplinas que propenden a comprender lo general, sintetizando lo especial. El humanismo, por tanto, siendo lo inmediatamente necesario a la humanidad, en esta época, tiende a quedar desplazado.

Enfocar a las Ciencias Sociales sólo como una tecnología de medición -cuantitativa y cualitativa de la realidad- las disocia de la multidisciplina humanista y poco a poco las coloca como un instrumento cómodo a las actividades comerciales. Por ello concluyo que una de nuestras tareas prioritarias es buscar la integración de las Ciencias Sociales, a partir de la formación misma del alumnado - ampliar la base teórica, hacer más eficaz aún la metodología e inspirar en todos una curiosidad por la explicación de los fenómenos sociales, por comprender lo misterioso del "alma" de la sociedad.

En el mundo de hoy la gran diversificación del saber hace que sea necesario a todos sobrepasar el estrecho límite de las "profesiones" y todos nosotros terminamos adquiriendo, si no por el propio interés, por la fuerza de los tiempos, una segunda profesión o una disciplina complementaria del saber. Ya desde las aulas, un estudiante universitario, si lo es realmente, debe saber buscar estos "saberes" complementarios. Mejor cientista social será quien a la vez domine algún arte, o que esté firmemente entrenado en la crítica intelectual.

El camino futuro de la universidad tendrá que ser el de abrir más los contactos internos entre sus facultades y sus departamentos para favorecer estos encuentros y la mutua "polinización" de las ideas.

Así, bajo la protección y la inspiración de los humanistas integrales que nos preceden, como lo es ejemplarmente Goethe, podríamos fabricar, colectivamente, un odre nuevo, fuerte, para contener el fermento del cambio.

La creación de una nueva Facultad de Ciencias Sociales es el inicio de una actividad nueva en nuestra universidad: supone que su función principal es el estudio de la realidad social contemporánea y que deberá ser un centro de investigación a la vez interno y relacionado multidisciplinariamente. La tarea de la formación profesional debe ser la proyección de dicho saber. ¡Cuidado si al guardar el vino nuevo lo echamos en un odre viejo! 